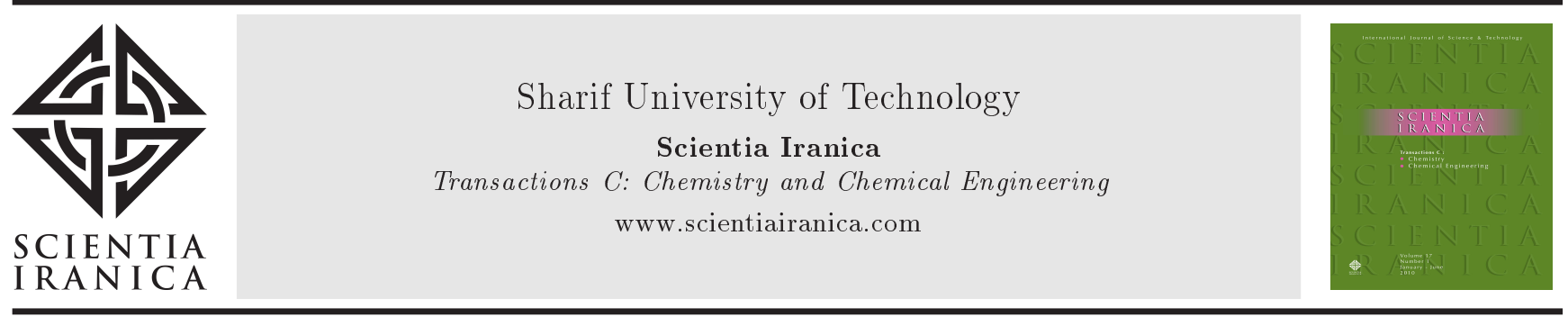

\title{
Influence of calcination parameters on the properties of alumina as a catalyst support
}

\author{
S. Komeili ${ }^{\mathrm{a}}$, M. Takht Ravanchi ${ }^{\mathrm{b}}$ and A. Taeb ${ }^{\mathrm{a}, *}$ \\ a. Department of Chemical Engineering, Iran University of Science and Technology, Tehran, P.O. Box 16765163, Iran. \\ b. National Petrochemical Company, Petrochemical Research and Technology Company, Tehran, P.O. Box 1435884711, Iran. \\ Received 22 November 2014; received in revised form 21 October 2015; accepted 21 November 2015
}

\section{KEYWORDS}

Alumina;

Calcination;

Acidic property;

Textural;

Structure.

\begin{abstract}
The preparation history of $\mathrm{Al}_{2} \mathrm{O}_{3}$ strongly determines its properties for the application as a catalyst support. The interaction of calcination heating rate and temperature and its influence on the structural, textural, and acidic properties of alumina were studied. Commercial $\gamma$-alumina was calcined at $800^{\circ} \mathrm{C}, 900^{\circ} \mathrm{C}, 1000^{\circ} \mathrm{C}, 1050{ }^{\circ} \mathrm{C}$, $1100^{\circ} \mathrm{C}$, and $1150^{\circ} \mathrm{C}$ by $2.5^{\circ} \mathrm{C} / \mathrm{min}, 5^{\circ} \mathrm{C} / \mathrm{min}$, and $10^{\circ} \mathrm{C} / \mathrm{min}$. By increasing temperature up to $1050^{\circ} \mathrm{C}$, transition aluminas $(\gamma, \delta$, and $\theta)$ were reported, but the heating rate accelerated phase transformation and changed the amount of each phase in the samples. At $1100^{\circ} \mathrm{C}$ and $1150^{\circ} \mathrm{C}, \alpha$-alumina appeared. Mesopore alumina with different surface areas $\left(265-126 \mathrm{~m}^{2} / \mathrm{g}\right)$ was synthesized at calcination temperature from $800^{\circ} \mathrm{C}$ to $1050^{\circ} \mathrm{C}$; when temperature reached $1100^{\circ} \mathrm{C}$, the surface area decreased drastically and was around $14 \mathrm{~m}^{2} / \mathrm{g}$. Interaction of heating rate on the temperature had minimal effect on the surface area of samples, but considerable effect on the acidic properties. The intensity of acidic properties was affected by heating rate with nonlinear profiles. By increasing the heating rate, the ratio of $\mathrm{Al}$ cations occupied tetrahedral per octahedral sites and defect of crystal structures increased, so the surface acidity of aluminas was increased.
\end{abstract}

(C) 2016 Sharif University of Technology. All rights reserved.

\section{Introduction}

The nature of support is an important parameter that influences the activity, selectivity, and lifespan of a catalyst; so, the support choice in the preparation of catalyst is considerable. The surface properties of the support influence the characters of active sites, while they can display a synergistic effect on the performances of the catalyst $[1,2]$.

Alumina is widely used as the catalyst support and adsorbent in the chemical and petrochemical processes due to surface area, pore volume, pore sizes, structures, and acid/base characters. Aluminium oxide

\footnotetext{
*. Corresponding author. Tel.: +98 2188620603 ;

Fax: +982173021633

E-mail address: Taeb@iust.ac.ir (A. Taeb)
}

can exist in several phases, i.e. $\gamma_{-}^{-}, \eta_{-}, \beta_{-}, \chi_{-}^{-}, \kappa^{-}, \delta_{-}, \theta_{-}$, and $\alpha$-alumina. Alpha-alumina is the thermodynamically stable and well-crystallized alumina and is usually obtained at high temperatures. The other phases are called transition or metastable phases [3].

Differences in crystalline structure may result in changes in physical and chemical properties of aluminas as the support [3,4]. The alumina phases have two broad categories of oxygen anions arrangements, a Face-Centered Cubic (FCC) or a Hexagonal ClosePacked (HCP). The $\mathrm{Al}_{2} \mathrm{O}_{3}$ structures, based on FCC packing of oxygen, include $\gamma$ (cubic), $\delta$ (monoclinic), and $\theta$ (either tetragonal or orthorhombic), whereas the $\mathrm{Al}_{2} \mathrm{O}_{3}$ structures, based on $\mathrm{HCP}$ packing, are represented by $\alpha$ (trigonal), $\kappa$ (orthorhombic), and $\chi$ (hexagonal) phases [5-7].

The sequence of phases formed and temperatures 
required for each phase transformation depend on the starting materials (alumina precursors), synthesizing route, and thermal treatments [8,9].

Alumina obtained from boehmite is usually used as a catalyst support due to its favor in textural properties with a wide range of surface areas (from 2-500 $\mathrm{m}^{2} / \mathrm{g}$ ), porosities, crystalline structures, and surface acidity $[10,11]$. The approximate temperatures required for the phase transformations in the crystallization sequences are $[9,12]$ :

$$
\begin{aligned}
\text { Boehmite } & \rightarrow \gamma\left(300-500^{\circ} \mathrm{C}\right) \rightarrow \delta\left(800^{\circ} \mathrm{C}\right) \\
& \rightarrow \theta\left(900^{\circ} \mathrm{C}\right) \rightarrow \alpha\left(\geq 1200^{\circ} \mathrm{C}\right) .
\end{aligned}
$$

Water between the crystal planes of boehmite is removed by heat treatment, and small pores, which originate in spaces within the particles, are formed and distinct crystal structures are appeared $[11,13]$.

The calcination conditions impact on the properties of aluminas, such as structural, textural, and acidity characteristics. The calcination variables, such as temperature, time span, and heating rate interact with each other and influence the complexity of physical and chemical phenomena that occur during the thermal treatment of alumina precursors $[14,15]$.

In many papers, the effect of calcination temperature on the final properties of aluminas has been investigated and reported, extensively $[8,10,16,17]$, but the heating rate has been less imperceptible as an experimental variable. The effect of time span on textural properties is not statistically significant at calcination temperature; but it is sufficient for thermal stabilization of alumina $[10,15]$.

In this study, different aluminas were prepared by calcining at various conditions. The end-temperature and heating rate were considered as calcination parameters and their effect on the properties of alumina were investigated.

\section{Experimental}

\subsection{Materials and methods}

Commercial spherical $\gamma-\mathrm{Al}_{2} \mathrm{O}_{3}$ (BET: $210.13 \mathrm{~m}^{2} / \mathrm{g}$ and pore volume: $0.53 \mathrm{~cm}^{3} / \mathrm{g}$ ) was supplied from Sasol Co. $\gamma-\mathrm{Al}_{2} \mathrm{O}_{3}$ was calcined by 3 levels of heating rate, i.e. $2.5^{\circ} \mathrm{C} / \mathrm{min}, 5^{\circ} \mathrm{C} / \mathrm{min}$, and $10^{\circ} \mathrm{C} / \mathrm{min}$; and by 6 levels of end-temperature, i.e. $800^{\circ} \mathrm{C}, 900^{\circ} \mathrm{C}, 1000^{\circ} \mathrm{C}$, $1050^{\circ} \mathrm{C}, 1100^{\circ} \mathrm{C}$, and $1150^{\circ} \mathrm{C}$. The remaining time was $3 \mathrm{~h}$ at end-temperature.

\subsection{Characterization}

The X-Ray Diffraction (XRD) pattern of calcined $\mathrm{Al}_{2} \mathrm{O}_{3}$ support was carried out by using a X-ray diffractometer (Model GNRMPD 3000) with $\mathrm{Cu}-\mathrm{K} \alpha$ radiation at $40 \mathrm{kV}$ and $30 \mathrm{~mA}$. The mean crystal size of
$\mathrm{Al}_{2} \mathrm{O}_{3}$ support was estimated by the half-width of the corresponding XRD peaks using Scherrer equation [18].

The BET surface areas of the products were determined by $\mathrm{N}_{2}$ physisorption using a sorption analyzer, Quantachrome Nova 2200. The BET measurements, nitrogen adsorption-desorption isotherms, and pore structure analysis were conducted at $77 \mathrm{~K}$. The pore size distribution was determined by the Barrett-JoynerHalenda (BJH) method for mesopores and Density Functional Theory (DFT) for micropores.

The water-displacement method was used for measuring pore volume of macropores. In this method, dry sample was weighted, then immersed in water at $70^{\circ} \mathrm{C}$ for $1 \mathrm{~h}$. The sample was cooled to ambient temperature. The difference between weights of saturated sample in air and dry sample was that of water displacement in pores. The pore volume was calculated by using water density [19].

Temperature-Programmed Desorption (TPD) of $\mathrm{NH}_{3}$ was performed in BELCAT A. Adsorption was carried out at $60^{\circ} \mathrm{C}$ in a mixture of $\mathrm{NH}_{3}(2.5 \mathrm{~mL} / \mathrm{min})$ and $\mathrm{He}(47.5 \mathrm{~mL} / \mathrm{min})$ flow for $1 \mathrm{~h}$. The product was then exposed to $\mathrm{He}$ for $30 \mathrm{~min}$ at $60^{\circ} \mathrm{C}$ to remove all the physically adsorbed species before starting the temperature program. The samples adsorbed ammonia at $60^{\circ} \mathrm{C}$, and heated up to $700^{\circ} \mathrm{C}$ at heating rate $10^{\circ} \mathrm{C} / \mathrm{min}$. Desorption signals were monitored by using a TCD spectrometer. The amount of acid sites on the catalyst surface was proportional to desorption amount of ammonia.

\section{Results and discussion}

The X-ray diffraction patterns of samples calcined between $800^{\circ} \mathrm{C}$ to $1150^{\circ} \mathrm{C}$ by $5^{\circ} \mathrm{C} / \mathrm{min}$ heating rate are shown in Figure 1. Different transition aluminas $(\gamma, \delta$, and $\theta)$ were obtained at $800^{\circ} \mathrm{C}$ and $900^{\circ} \mathrm{C}$ that were confirmed according to the International Centre for Diffraction Data (ICDD). The strongest diffraction peak of $\gamma$-alumina is at the $2 \theta$ value of $45.8^{\circ}$ (ICDD card No. 10-0425). The first strongest diffraction peaks of $\delta$ and $\theta$ are at the same $2 \theta$ value of $67.3^{\circ}$. The second strongest diffraction peak of $\delta$-alumina is at the $2 \theta$ value of $45.5^{\circ}$ (ICDD card No. 4-0877) and for $\theta$-alumina is at the $2 \theta$ value of $45.0^{\circ}$ (ICDD card No. 11-0517). By increasing the temperature up to $1000^{\circ} \mathrm{C}, \gamma$-alumina disappeared and at the dominant phases, $\delta$-alumina was formed; the broad peak means poor crystallization of the samples. At $1050^{\circ} \mathrm{C}$, two transition ( $\delta$ and $\theta$ ) aluminas were formed and at $1100^{\circ} \mathrm{C}$, crystal phase of $\alpha$-alumina was obtained. The sharp XRD lines were observed for samples that were calcined at $1100^{\circ} \mathrm{C}$ and $1150^{\circ} \mathrm{C}$, indicating appearance of a well crystallized alpha alumina.

In Figure 2, the effect of heating rate on the formation of transition alumina at $1050^{\circ} \mathrm{C}$ is shown. 


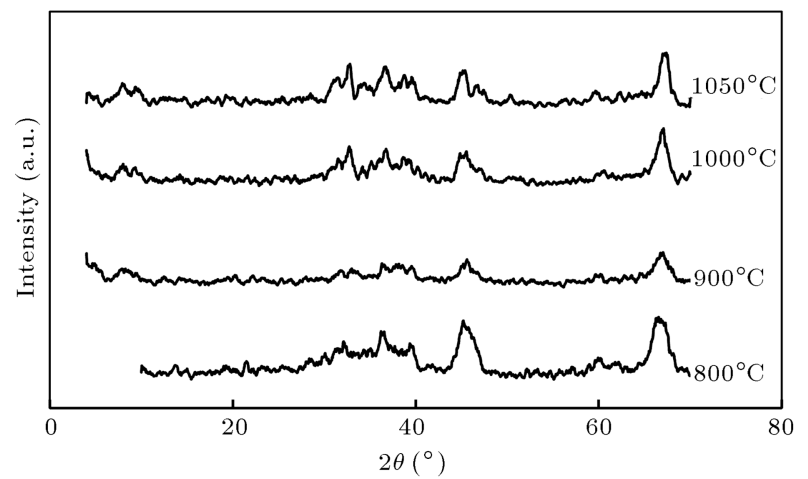

(a)

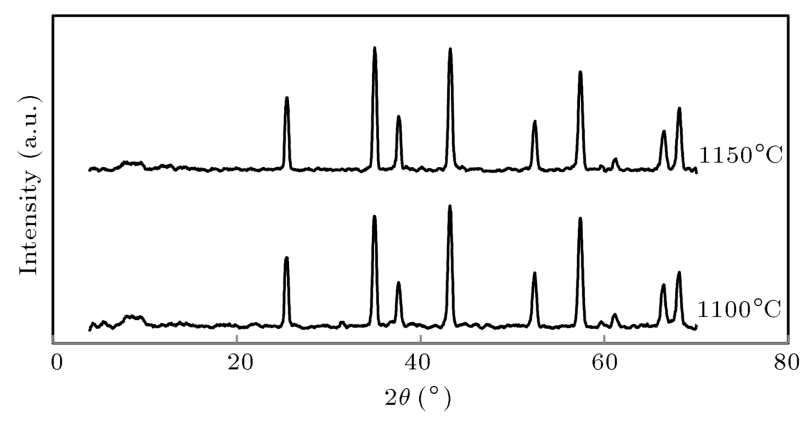

(b)

Figure 1. XRD patterns of calcined alumina at (a) $800^{\circ} \mathrm{C}-1050^{\circ} \mathrm{C}$, and (b) $1100^{\circ} \mathrm{C}$ and $1150^{\circ} \mathrm{C}$ by $5^{\circ} \mathrm{C} / \mathrm{min}$.

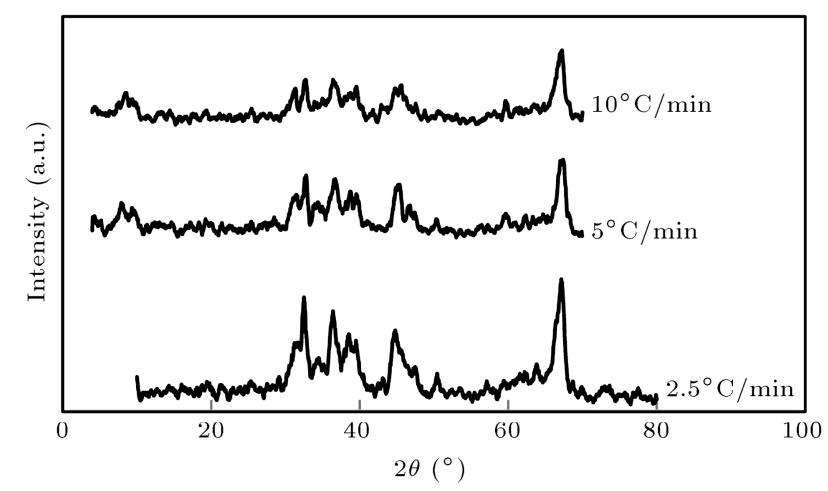

Figure 2. XRD patterns of calcined alumina at $1050^{\circ} \mathrm{C}$ by using $2.5^{\circ} \mathrm{C} / \mathrm{min}, 5^{\circ} \mathrm{C} / \mathrm{min}$, and $10^{\circ} \mathrm{C} / \mathrm{min}$.

Diffraction patterns of other samples were omitted, since they were similar to those shown in Figures 1 and 2 .

Estimated phase percent and crystal size of each transition alumina that was indicated in XRD patterns is given in Table 1 .

All $\gamma, \delta$ and $\theta$ transition aluminas were existent in those samples that calcined by $2.5^{\circ} \mathrm{C} / \mathrm{min}$ heating rate and end temperature up to $1050^{\circ} \mathrm{C}$. By increasing the temperature, the crystal sizes decreased and the density of aluminas increased, as the vacant space in alumina structure decreased [12]. But, $\gamma$ alumina was detected only at $800^{\circ} \mathrm{C}$ and $900^{\circ} \mathrm{C}$ at $5^{\circ} \mathrm{C} / \mathrm{min}$ heating rate and was not reported by increasing the heating rate up to $10^{\circ} \mathrm{C} / \mathrm{min}$. Therefore, the phase transformation was accelerated by increasing heating rate. Crystal sizes did not change, significantly, as crystal structures changed permanently. The structures with lower grade of crystallite and defect crystal planes were formed at 5 and $10^{\circ} \mathrm{C} / \mathrm{min}$ in comparison to $2.5^{\circ} \mathrm{C} / \mathrm{min}$ heating rates.

The changes of the crystal structure from FCC to $\mathrm{HCP}$ appeared when the transition aluminas were converted to $\alpha$-alumina. The variation in coordination is caused by the transformation of aluminium tetrahedrons to octahedrons, which is only finalized at temperatures higher than $1100^{\circ} \mathrm{C}[20]$. By comparing crystal sizes between 1100 and $1150^{\circ} \mathrm{C}$, i.e. $\alpha$-alumina, it can be concluded that the crystals were grown and partial sintering happened at $2.5^{\circ} \mathrm{C} / \mathrm{min}$ heating rate, but the crystal sizes did not significantly change at $5^{\circ} \mathrm{C} / \mathrm{min}$, and $10^{\circ} \mathrm{C} / \mathrm{min}$. Therefore, the calcination heating rate can affect the sintering properties of aluminas [21].

This phase transition sequence is the same as the transition alumina sequence obtained from boehmite source, while the $\gamma$ phase is changed to $\delta$ and $\theta$ and finally, $\alpha$ phase is formed. In fact, the structural alumina system from one extreme to another will turn out to be quite important for the definition and understanding of some transition phase properties [22].

The $\mathrm{N}_{2}$ adsorption-desorption isotherms and pore size distribution curves calculated by BJH method for samples prepared by $5^{\circ} \mathrm{C} / \mathrm{min}$ heating rate are shown in Figures 3 and 4, respectively.

Isotherms of calcined samples at $800^{\circ} \mathrm{C}$ to $1050^{\circ} \mathrm{C}$ were similar to type IV of IUPAC classification, which was related to mesopores. The hysteresis loops were H2 type of IUPAC [23]. The monolayer adsorption occurred around a relative pressure of 0.69 for these samples. So, the proportion of micropores to mesopores was constant by increase in calcination temperature. Adsorption-desorption isotherms of samples at $1100^{\circ} \mathrm{C}$ and $1150^{\circ} \mathrm{C}$ were the same as type III of IUPAC that is for macropores. Therefore, it confirmed that $\alpha$-alumina was formed. As isotherms of other heating rates were similar to those in Figure 3, they were omitted.

The pore size distributions of some calcined samples using BJH method based on desorption data are shown Figure 4. The maximum pore size that can readily be measured is around $100 \mathrm{~nm}$. The pore size distributions were the same and average pore diameter was around $9 \mathrm{~nm}$ by increasing calcination temperatures from $800^{\circ} \mathrm{C}$ to $1050^{\circ} \mathrm{C}$. The broad distribution between $2 \mathrm{~nm}$ to $100 \mathrm{~nm}$ was indicated for samples at $1100^{\circ} \mathrm{C}$ and $1150^{\circ} \mathrm{C}$, because they had major pores larger than $100 \mathrm{~nm}$.

Figure 5 shows the effect of calcination temperature and heating rate on the specific surface areas of the alumina supports that were measured by BET method. 
Table 1. Estimated phase percent and calculated crystal sizes of alumina.

\begin{tabular}{|c|c|c|c|c|c|c|c|c|c|}
\hline \multirow{2}{*}{$\begin{array}{c}\text { Heating rate } \\
\qquad\left({ }^{\circ} \mathrm{C} / \mathrm{min}\right)\end{array}$} & \multirow{2}{*}{$\begin{array}{c}\mathrm{T} \\
\left({ }^{\circ} \mathrm{C}\right)\end{array}$} & \multicolumn{4}{|c|}{ Phase (\%) } & \multicolumn{4}{|c|}{ Crystal size (nm) } \\
\hline & & $\gamma$ & $\delta$ & $\theta$ & $\alpha$ & $\gamma$ & $\delta$ & $\theta$ & $\alpha$ \\
\hline \multirow{6}{*}{2.5} & 800 & 50 & 28 & 22 & - & 25.6 & 38.2 & 40.6 & - \\
\hline & 900 & 48 & 28 & 24 & - & 24.1 & 25.1 & 31.4 & - \\
\hline & 1000 & 41 & 31 & 28 & - & 23.1 & 11.2 & 16.4 & - \\
\hline & 1050 & 24 & 26 & 40 & - & 23.9 & 11.7 & 18.5 & - \\
\hline & 1100 & - & - & - & 100 & - & - & - & 23.8 \\
\hline & 1150 & - & - & - & 100 & - & - & - & 29.9 \\
\hline \multirow{6}{*}{5} & 800 & 50 & 28 & 22 & - & 15.2 & 22.7 & 22.11 & - \\
\hline & 900 & 46 & 28 & 26 & - & 44.45 & 36.44 & 18.14 & - \\
\hline & 1000 & - & 100 & - & - & - & 12.2 & - & - \\
\hline & 1050 & - & 51 & 49 & - & - & 19.1 & 17.7 & - \\
\hline & 1100 & - & - & - & 100 & - & - & - & 28.4 \\
\hline & 1150 & - & - & - & 100 & - & - & - & 27.4 \\
\hline \multirow{6}{*}{10} & 800 & $*$ & $*$ & $*$ & $*$ & - & 11.63 & - & - \\
\hline & 900 & * & $*$ & $*$ & $*$ & - & 21.3 & 12.5 & - \\
\hline & 1000 & $*$ & $*$ & $*$ & $*$ & - & 12.08 & 13.8 & - \\
\hline & 1050 & $*$ & $*$ & $*$ & $*$ & - & 11.4 & 26.3 & 28.3 \\
\hline & 1100 & - & - & - & 100 & - & - & - & 27.5 \\
\hline & 1150 & - & - & - & 100 & - & - & - & 25.6 \\
\hline
\end{tabular}

*: Not determined.

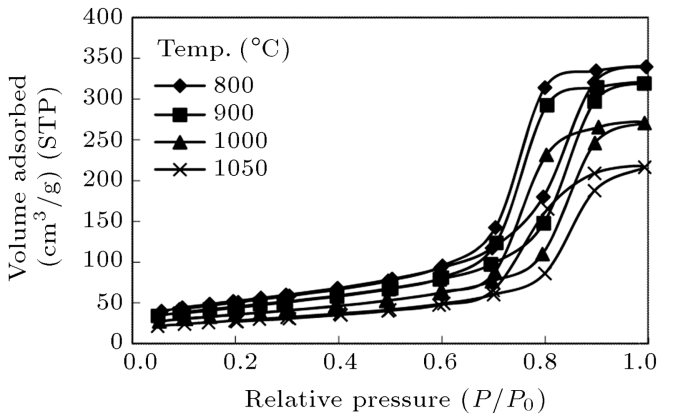

(a)

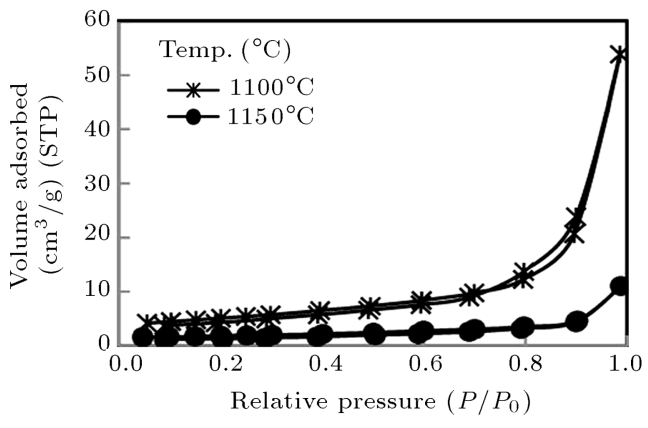

(b)

Figure 3. Adsorption-desorption isotherms of alumina calcined at $800^{\circ} \mathrm{C}-1150^{\circ} \mathrm{C}$ by using $5^{\circ} \mathrm{C} / \mathrm{min}$.

The specific surface areas decreased by increasing the calcination temperature. This is attributed to the changes in the size of alumina crystal, caused by the destruction of some small pores. When temperature increases from $800^{\circ} \mathrm{C}$ to $1050^{\circ} \mathrm{C}$, the surface area, however, decreases quickly; but, the pore diameter remains unchanged. Then, both the surface area and the pore diameter drop as the pore structure collapses with increasing temperature to $1100^{\circ} \mathrm{C}$ [10].

The specific pore volumes calculated by BJH method for mesopores and DFT method for micropores and estimated with water displacement for macropores are shown in Figure 6. By increasing temperature, specific pore volume decreased. The average propor- tion of DFT and BJH pore volumes for samples at end-temperature up to $1050^{\circ} \mathrm{C}$ was around 0.25 . This means that micropores were changed commensurate with mesopores.

For samples calcined at $1100^{\circ} \mathrm{C}$ and $1150^{\circ} \mathrm{C}$, micro and mesopore volumes drastically decreased. Sintering of particles may occur during the heat treatment, which could reduce pore volume after calcination at higher temperatures. Sintering may also be responsible for decreasing surface area and increasing pore size, which is signified by the collapse of porous structure characteristics of the low-temperature phases and the consequent diminishing of the surface area [16].

The pore size distribution, shapes of $\mathrm{N}_{2}$ adso- 


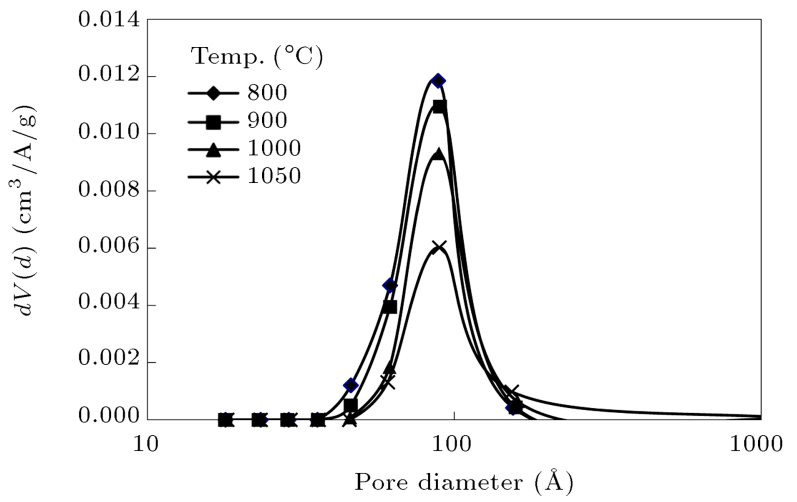

(a)

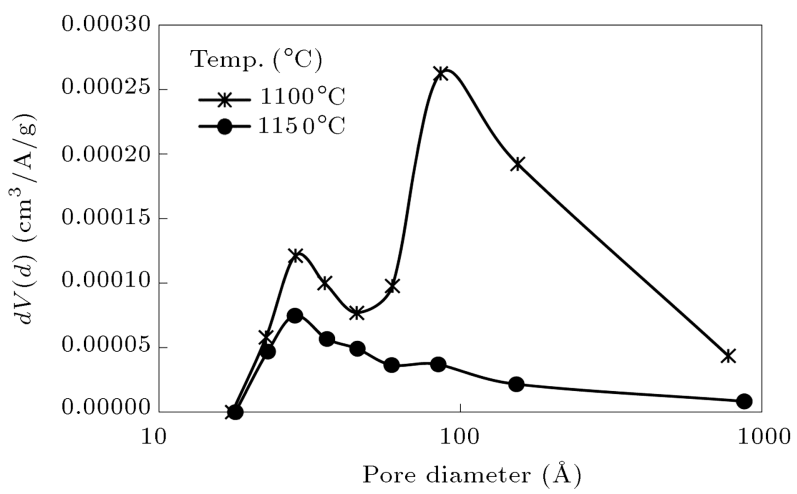

(b)

Figure 4. Pore size distribution of alumina calcined at (a) $800^{\circ} \mathrm{C}-1050^{\circ} \mathrm{C}$, (b) $1100^{\circ} \mathrm{C}$ and $1150^{\circ} \mathrm{C}$.

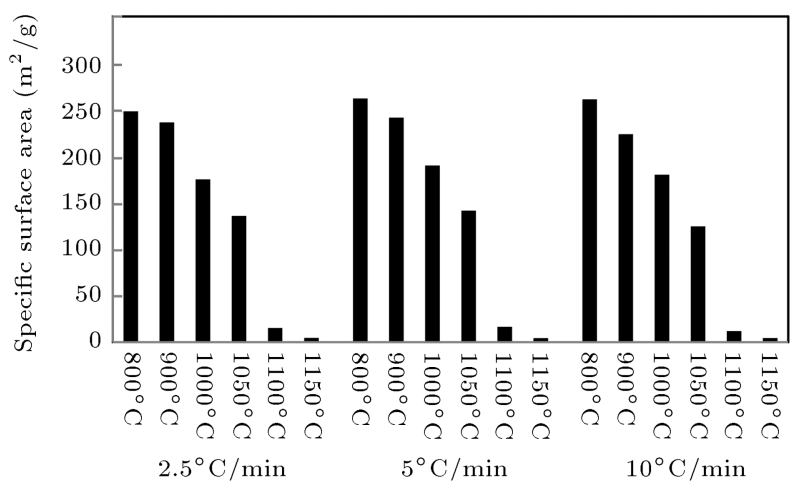

Figure 5. Effect of calcination temperature and heating rate on the surface area.

rption-desorption isotherms, and hysteresis loops are basically similar at different heating rates, but only differ in quantity.

Textural properties of alumina are the key parameters of the catalyst support usage. Calcination conditions had different effects on the surface area and porosity. Surface area and pore volume were less influenced by increasing heating rate, but the calcination temperature had a strong influence on the surface area due to changes in crystal structures and densification of transition aluminas; but, it had a moderate effect on the pore volumes $[10,14,24]$.

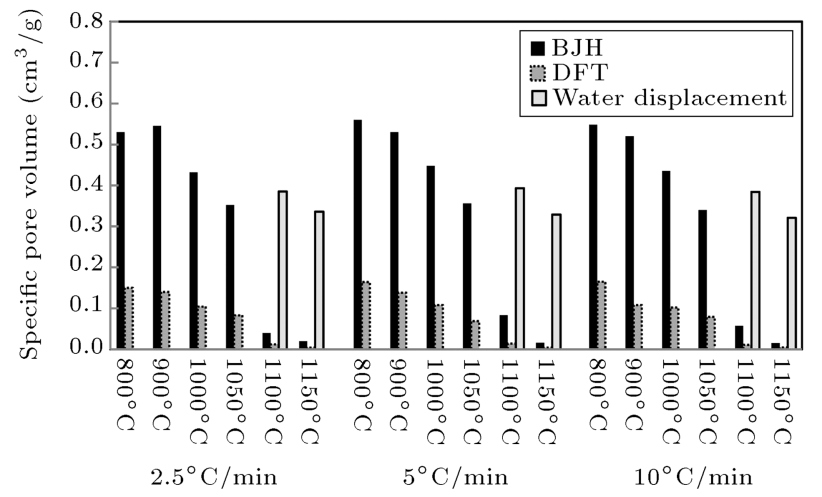

Figure 6. Specific pore volume measured by BJH method for mesopores, DFT for micropores, and water

displacement for macropores at different calcination temperatures and heat rates.

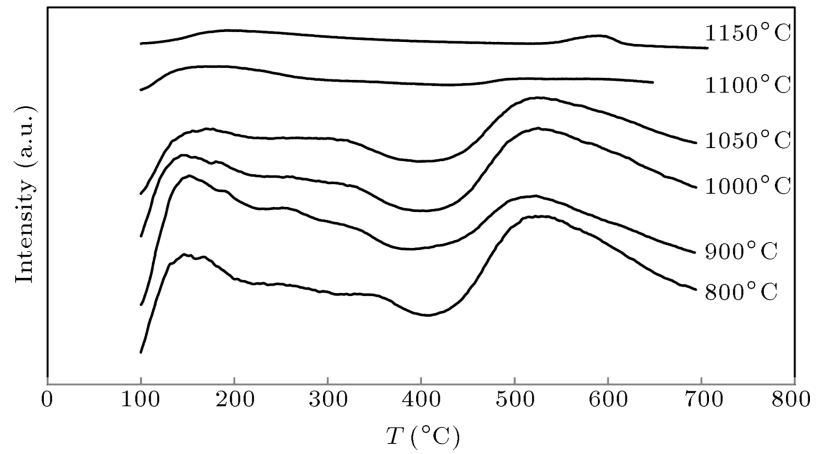

Figure 7. $\mathrm{NH}_{3}$-TPD spectra of samples calcined at $800-1150^{\circ} \mathrm{C}$ by $5^{\circ} \mathrm{C} / \mathrm{min}$.

Temperature programmed desorption of ammonia $\left(\mathrm{NH}_{3}-\mathrm{TPD}\right)$ is a technique to determine the surface concentration and strength of acid sites [25]. This technique was used to correlate acidic properties of alumina with calcination conditions.

$\mathrm{NH}_{3}$-TPD profiles of samples calcined at different temperatures by $5^{\circ} \mathrm{C} / \mathrm{min}$ heating rate are shown in Figure 7.

There are two peaks for every sample, which indicate the presence of two acid sites on these alumina mixing phases. The low temperature peak (around $150^{\circ} \mathrm{C}$ ) could be attributed to weak acid sites, while the high temperature peak (around $550^{\circ} \mathrm{C}$ ) could be associated with strong acid sites. For samples $1100^{\circ} \mathrm{C}$ and $1150^{\circ} \mathrm{C}$, tiny peaks existed, which confirmed that $\alpha$-alumina had low acidity in comparison with the other alumina phases. The decline in the acid site can be ascribed to the surface reconstruction. This may be attributed to the greater amount of low coordination surface aluminium ions due to more surface dehydroxylation [26].

The amount of desorbed ammonia, which is considered the same as the acid site concentration as $s$ function of calcination condition, is shown in Figure 8. The aluminas contained a larger number of 


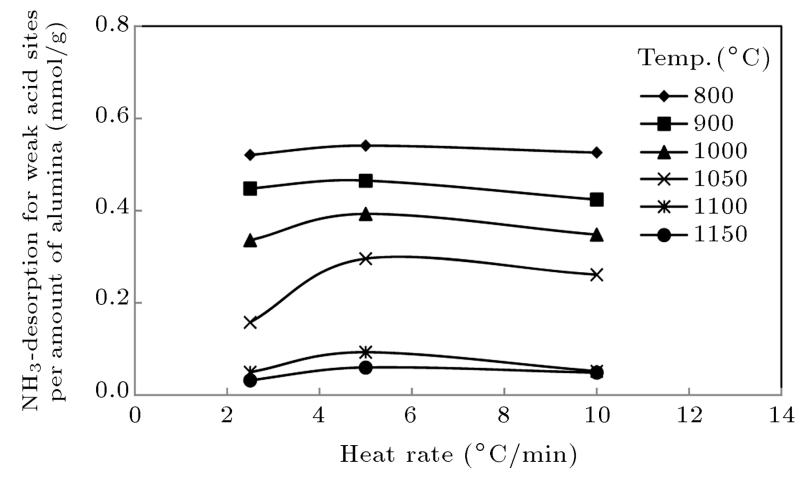

(a)

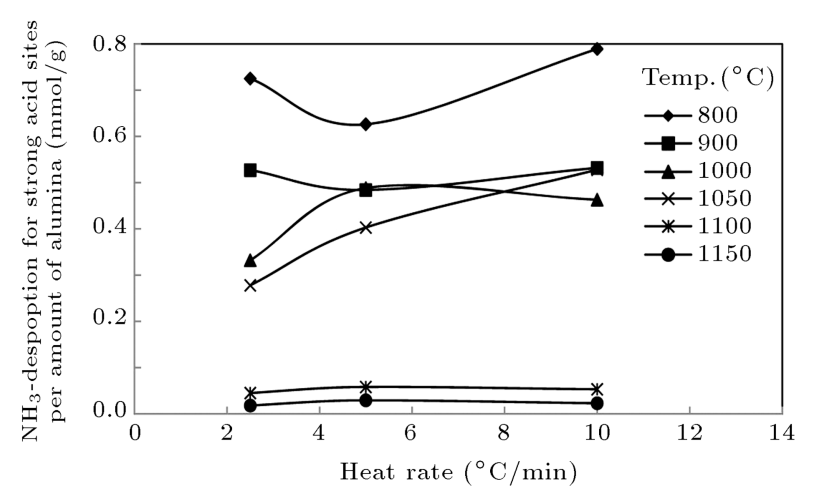

(b)

Figure 8. Amounts of $\mathrm{NH}_{3}$-desorption vs. calcination heating rate at $800-1150^{\circ} \mathrm{C}$ for (a) weak and (b) strong acid sites.

strong acid sites than weak ones. The amounts of two types of acidic sites decreased by increasing calcination temperature and this dependency was linear, similar to the effect of temperature on the surface area of aluminas. The effect of temperature on the strong acid sites was drastic.

The removal of $\mathrm{OH}$ group during high temperature treatment creates coordinative unsaturated surface cations that are placed on the tetrahedral and octahedral Al coordination. The partly uncoordinated metal cations and oxide onions that lie on the surface of aluminas can act as acids and bases, respectively, according to the Lewis definition. The strongest acid sites are considered to be the tetrahedral Al ions, which are mainly located in crystallographically defective configurations and yield the reactive surface sites; they tend to be annihilated at high temperature [3].

The XRD results confirmed that the calcination conditions had an intensive effect on the variation structures of aluminas. The existence of amorphous phases shows that the crystal defects the samples; therefore, it shapes acidic sites on the alumina surface.

The heating rate had influence on the concentration of acid sites; therefore, this profile was not linear. For the amount of weak acidic sites, it was convex; but, for strong acidic sites, it was convex up to $1000^{\circ} \mathrm{C}$ and concave at higher temperature than $1000^{\circ} \mathrm{C}$, which can be seen in Figure 8. This indicated that heating rate had notable effect on the acidic properties of each alumina phase. This finding was confirmed by Ros et al. who modelled the effect of calcination properties on the physiochemical properties of transition aluminas; the concentration of acid sites varied with the square of heating rate. At low temperature, the concentration isotherms of strong acid sites presented a minimum, but at high temperature, they presented a maximum [14].

High heating rate, since samples were exposed to higher temperature for a shorter time, favored for formation of a larger amount of strong acid sites, as their formation occurred with low surface area loss [14].

The intensiveness of acid sites could be shown by maximum temperature of peaks. The first peak could be regarded as weak acid sites with maximum temperature around $150^{\circ} \mathrm{C}$; so, heating rate did not have significant effect on the weak acidic intensity for transition aluminas.

For strong acid sites, maximum temperature was around $510^{\circ} \mathrm{C}$ to $525^{\circ} \mathrm{C}$. The heating rate had influence on the intensity of strong acid sites of transition aluminas. The profiles were similar to those of quadratic function and convex form, as shown in Figure 9.

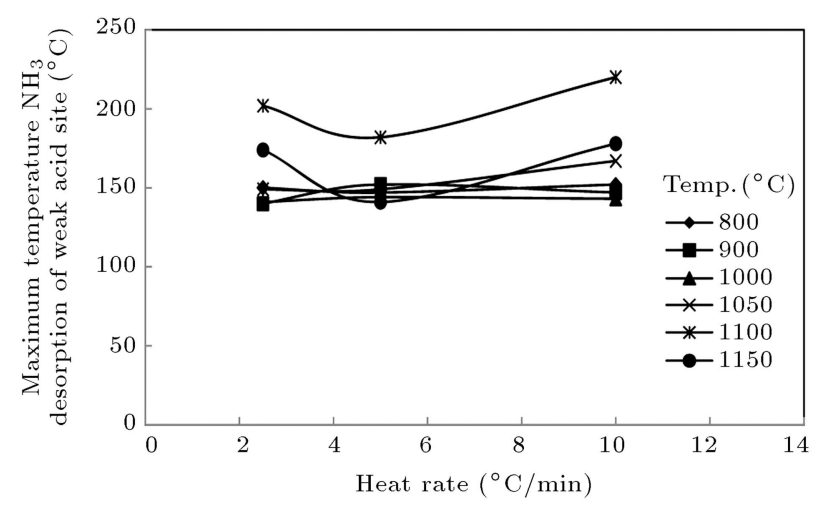

(a)

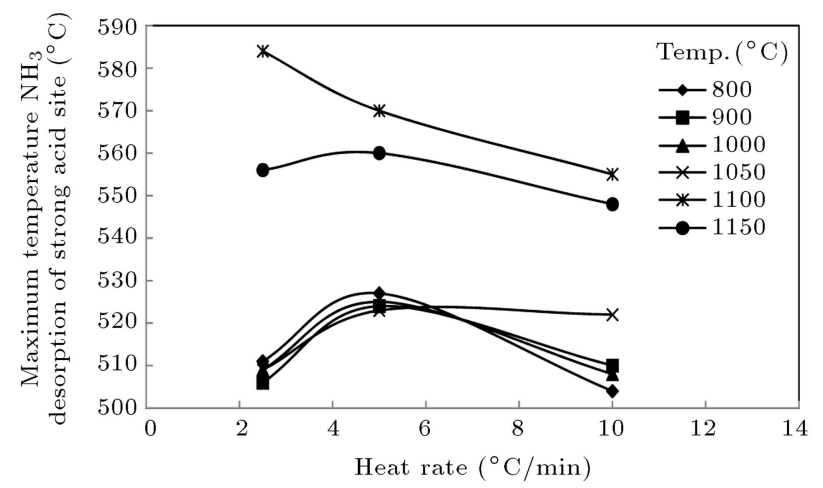

(b)

Figure 9. Maximum peak temperature at $800-1150^{\circ} \mathrm{C}$ for (a) weak and (b) strong acid sites. 
After dehydroxylation during high temperature treatment, the surface develops Lewis acidity on the uncoordinated $\mathrm{Al}^{\delta^{+}}$sites [14]. The intensity of the desorption peaks gradually decreases with the increase in calcination temperature, suggesting that less acidic sites are present in the samples [26].

With the definition of Lewis acidity, acidic supports are associated with a low electron-richness on the support oxygen atoms. It is found that a lower electron richness of the support oxygen atoms leads to a higher ionization potential of the active metal particles in catalysts. As the acidity of the support increases, the electron richness of the support $\mathrm{O}$ atoms decreases $[27,28]$.

All calcination variables had influence on the alumina acidity. The most important element was the calcination temperature, a key factor that changed concentration of the acid site. The calcination temperature changed the transition alumina structure. Transition alumina was a mix of spinel forms with trivalent and divalent $\mathrm{Al}$ cations that occupied the tetrahedral or octahedral sites. The coordination of the unsaturated aluminium atoms was varied and dependent on the formed crystal plans $[22,29]$. Ratio of $\mathrm{Al}$ cations occupying tetrahedral per octahedral sites, surface crystal plane, and defect of crystal structure were affected by the acidity of alumina. The effects of the time at the final temperature and cooling temperature were not considered as these parameters were not statistically significant over the number of strong acid sites $[10,25]$.

\section{Conclusion}

As investigated, the alumina crystal structures changed permanently by increasing temperature, but the heating rate accelerated the phase transformation. This acceleration caused shaping more defect crystal plane. The temperature had a strong effect on the surface area and a moderate one on the pore volume. The surface area decreased by increasing temperature due to change of alumina structure and densification. The heating rate had not notable interaction with temperature to change surface area.

The amounts of weak and strong types of acidic sites decreased by increasing calcination temperature and this dependency was linear, similar to the effect of temperature on the surface area of aluminas; but, the effect of temperature on the strong acid sites was drastic.

High heating rate, since the samples were exposed to high temperature for a short time, favored the formation of a larger amount of strong acid sites to create more surface defects. The strongest acid sites are considered to be the tetrahedral $\mathrm{Al}$ ions, which are mainly located at defective configurations of crystals.

\section{Acknowledgments}

Authors gratefully acknowledge the financial support received in the form of a research grant (project No. 870249110) from the National Petrochemical Company-Research and Technology (NPC-RT), Iran.

\section{References}

1. Carre, S., Santacesaria, E. and Gelosa, D. "Basic behavior of alumina in the presence of strong acids", Ind. Eng. Chem. Prod. Res. Dev., 16(1), pp. 45-47 (1977).

2. Trueba, M. and Trasatti, S.P. " $\gamma$-alumina as a support for catalysts: A review of fundamental aspects", Eur. J. Inorg. Chem., 17, pp. 3393-3403 (2005).

3. Komhom, S., Mekasuwandumrong, O., Praserthdam, $\mathrm{P}$. and Panpranot, J. "Improvement of $\mathrm{Pd} / \mathrm{Al}_{2} \mathrm{O}_{3}$ catalyst performance in selective acetylene hydrogenation using mixed phases $\mathrm{Al}_{2} \mathrm{O}_{3}$ support", Catal. Commun., 10, pp. 86-91 (2008).

4. Karagedov, G.R. and Myz, A.L. "Preparation and sintering pure nanocrystalline $\alpha$-alumina powder", $J$. Euro. Ceram. Soc., 32, pp. 219-225 (2012).

5. Levin, I. and Brandon, D. "Metastable alumina polymorphs: Crystal structures and transition sequences", J. Am. Ceram. Soc., 81(8), pp. 1995-2012 (1998).

6. Liu, S., Zhang, L. and An, L. "Phase transformation of mechanically milled nano-sized $\gamma$-alumina", $J$. Am. Ceram. Soc., 88(9), pp. 2559-2563 (2005).

7. Bossert, J. and Fidancevska, E. "Effect of mechanical activation on the sintering of transition nanoscaled alumina", Sci. Sinter., 39, pp. 117-125 (2007).

8. Sivaraj, Ch., Contescu, C. and Schwarz, J.A. "Effect of calcination temperature of alumina on the adsorption/impregnation of $\mathrm{Pd}(\mathrm{II})$ compounds", J. Catal., 132, pp. 422-431 (1991).

9. Iaponeide, M., Macedo, F., Aparecido, C., Carla, B. and Osawa, C. "Kinetics of the $\gamma$ to $\alpha$-alumina phase transformation by quantitative X-ray diffraction", $J$. Mater. Sci., 42, pp. 2830-2836 (2007).

10. Sun, Z., Zheng, T., Bo, Q., Du, M. and Forsling, W. "Effects of calcination temperature on the pore size and wall crystalline structure of mesoporous alumina", J. Coll. Inter. Sci., 319, pp. 247-251 (2008).

11. Trimm, D.L. and Stanislaus, A. "The control of pore size in alumina catalyst supports: a review", Appl. Catal., 21, pp. 215-238 (1986).

12. Zhang, X. "Nanocrystalline functional alumina and boehmite materials: synthesis, characterization and applications", $\mathrm{PhD}$ Thesis, Tampere University of Technology (2009).

13. Legros, C., Carry, C., Bowenc, P. and Hofmann, H. "Sintering of a transition alumina: Effects of phase transformation, powder characteristics and thermal cycle", J. Euro. Ceram. Soc., 19, pp. 1967-1978 (1999). 
14. Da Ros, S., Barbos, E., Schwaab, M., Calsavara, V. and Fernandes-Machado, N.R.C. "Modelling the effects of calcination conditions on the physical and chemical properties of transition alumina catalysts", Mater. Charact., 80, pp. 50-61 (2013).

15. Palmero, P., Lombardi, M. and Montanaro, L. "Effect of heating rate on phase and microstructural evolution during pressureless sintering of a nanostructured transition alumina", Int. J. Appl. Ceram. Technol., 6, pp. 420-430 (2009).

16. Cava, S., Tebcherani, S.M., Souza, I.A., Pianaro, S.A., Paskocimas, C.A., Longob, E. and Varela, J.A. "Structural characterization of phase transition of $\mathrm{Al}_{2} \mathrm{O}_{3}$ nanopowders obtained by polymeric precursor method", Mater. Chem. Phys., 103, pp. 394-399 (2007).

17. Sarikaya, Y., Sevin, I. and Akin, M. "The effect of calcination temperature on some of the adsorptive properties of fine alumina powders obtained by emulsion evaporation technique“, Powd. Tech., 116, pp. 109-114 (2001).

18. Takht Ravanchi, M., Rahimi Fard, M., Fadaee Rayeeni, S. and Yaripour, F. "Effect of calcination conditions on crystalline structure and pore size distribution for a mesoporous alumina", Chem. Eng. Commun., 202, pp. 493-499 (2015).

19. Manger, G.E. "Method-dependent values of bulk, crain, and pore volume as related to observed porosity", Geol. Surv. Bull., United State Gonvernment Printing Office, Washington, USA (1966).

20. Goldberg, S., Davis, J.A. and Hem, J.D. "The surface chemistry of aluminium oxides and gydroxides", In The Environmental Chemistry of Aluminum, G. Sposito, Ed., pp. 272-290, CRC Press, Florida, USA (1996).

21. Stanciu, L.A., Kodash, V.Y. and Groza, J.R. "Effects of heating rate on densification and grain growth during field-assisted sintering of $\alpha-\mathrm{Al}_{2} \mathrm{O}_{3}$ and $\mathrm{MoSi}_{2}$ powders", Metal. Mater. Trans. A, 32, pp. 2633-2638 (2001).

22. Corral Valero, M., Digne, M., Sautet, P. and Raybaud, P. "DFT study of the interaction of a single palladium atom with $\gamma$-alumina surfaces: The role of hydroxylation", Oil \& Gas Sci. Tech., 61, pp. 535-545 (2006).

23. Naumov, S. "Hysteresis phenomena in mesoporous materials", PhD Dissertation, University at Leipzig (2009).

24. Wq, J., Mb, Y., Ym, W. and My, H. "Synthesis of morphology-controlled mesoporous transition aluminas derived from the decomposition of alumina hydrates", Microporous Mesoporous Mater., 147, pp. 167-177 (2012).

25. Galiková, A. and Galík, A. "The global approach to TPD and isothermal adsorption-desorption kinetics", 30th Conf. SSCHE, Tatranské Matliare, SK, pp. 26-32 (2003).
26. Bazyari, A., Mortazavi, Y., Khodadadi, A.A., Thompson, L.T., Tafreshi, R. and Zaker, A. and Ajenifujah, O.T. "Effects of alumina phases as nickel supports on deep reactive adsorption of (4,6-dimethyl) dibenzothiophene: Comparison between $\gamma, \delta$, and $\theta$-alumina", Appl. Catal. B: Environ., 180, pp. 312-323 (2016).

27. Storozhenko, P.A., Aleshin, A.I., Dovganyuk, V.F. and Turkov, G.O. "Selecting heat treatment conditions of alumina supports to improve the quality of selective hydrogenation palladium catalysts", Catal. Ind., 2(3), pp. 282-286 (2010).

28. Komeili, S., Takht Ravanchi, M. and Taeb, A. "The influence of alumina phases on the performance of the $\mathrm{Pd}-\mathrm{Ag} / \mathrm{Al}_{2} \mathrm{O}_{3}$ catalyst in tail-end selective hydrogenation of acetylene", Appl. Catal. A: Gen., 502, pp. 287296 (2015).

29. Morterra, C., Magnacca, G. "A case study: surface chemistry and surface structure of catalytic aluminas, as studied by vibrational spectroscopy of adsorbed species", Catal. Today, 27, pp. 497-532 (1996).

\section{Biographies}

Samane Komeili received her BSc degree in Chemical Engineering in 2005. She has been a $\mathrm{PhD}$ candidate in Iran University of Science and Technology since 2011. Her research interests are in process modelling and heterogeneous catalysts. She researches on the selective hydrogenation supported catalysts. To date, she has published 7 scientific papers.

Maryam Takht Ravanchi holds a PhD in Chemical Engineering. She is a researcher in Catalyst research group in Petrochemical Research and Technology Company. Her research interests are in the fields of natural gas conversion and environmental research. Her recent research activities have focused on acetylene selective hydrogenation. She has more than ten years of experience in petrochemical industry as a process engineer and senior researcher and has about 50 publications as books and scientific articles.

Abbas Taeb has a chair in Chemical Engineering Department of Iran University of Science and Technology (IUST). He received PhD degree in Chemical Engineering from Graz University of Technology, Austria, in 1986. He was head of inorganic materials group, Chemical Engineering Department, and also IUST for many years. He has been supervisor of over $12 \mathrm{PhD}$ candidates. He has published over 50 papers in ISI journals. His research interests include cement and catalysts. He was selected as a distinguished professor in IUST and by Ministry of Science, in 1995 and 1996, respectively. 